\title{
An Analysis of Wind Power Generation on the Electric Transmission System of Southern Vietnam
}

\author{
MINH-HOA NGUYEN ${ }^{*}$, VAN-TAN TRAN ${ }^{1}$, TAN-HUNG PHAM $^{1}$, THANH-LUU CAO $^{2}$ \\ ${ }^{1}$ School of Engineering and Technology, Tra Vinh University, Tra Vinh, VIETNAM \\ ${ }^{2}$ Department of Electrical and Refrigeration, Vinh Long Vocational College, Vinh Long, VIETNAM
}

\begin{abstract}
Renewable energy is an emerging candidate in power generation for the compensation of the exhausted fossil fuel, in which wind energy plays an important role. However, how wind farms impact existing power systems has still been a subject on which many researchers are studying. This study has analyzed and evaluated the four wind farms consisting of Ca-Mau (300 MW), Bac-Lieu (99 MW), Soc-Trang (100 MW) and Tra-Vinh (33 MW) located in Southern Vietnam via using the commercial package, WAsP software. Ca-Mau wind farm has the highest planned rated capacity with $51.7 \%$ among the wind farms. Each wind farm is built from three different types of wind turbines (1 MW, $2 \mathrm{MW}$ and $3 \mathrm{MW}$ ). The estimation has shown that all of the wind farms could produce $2,265 \mathrm{GWh}$ annually, and the $3-\mathrm{MW}$ wind turbines are the most efficient and give the smallest losses for producing wind energy. The wind farms, with respect to environmentally friendly aspects, could avoid 978,544 $\mathrm{tCO}_{2}$ emitted to the environment annually. Additionally, the ETAP program has also been applied to simulate the effects of the proposed wind farms on the national power system including the disturbances from wind speeds, three-phase bus faults, tripping off wind farms and three-phase line faults on the power system. The results show that the wind farms are only slightly impacted.
\end{abstract}

Key-Words: Wind disturbance; three-phase fault; $\mathrm{CO}_{2}$ emission; transient stability; wind farm in Southern Vietnam.

Received: February 23, 2021. Revised: August 16, 2021. Accepted: August 31, 2021. Published September 7, 2021.

\section{Introduction}

Wind energy has been the fastest growing worldwide over decades. In last months of 2019, total wind power capacity of the world obtained 651 GW occupying $5.9 \%$ of the global energy production, in which total installed capacity in China was largest, achieving about 36\% [1]. In recent years, wind power potential and its impacts on distribution systems have been attractive subjects to many researchers. The potential of developing wind power in Algeria were detailed in [2]. A large amount of approximately $23,252 \mathrm{tCO}_{2}$ per year of released to environments could be avoided due to installing wind farms of 30 MW [3]. Similarly, three wind farms were built with the rated capacity of 30 MW each in $[4,5]$. Moreover, the potential of wind energy at Lootak - Zabol station in Iran was evaluated by Kiana Rahmani et at [6].

Reference [7] showed the potential for developing wind farms in Penghu Island, Taiwan. The analysis for the influences of wind generation stations on the power system was also analyzed in [8]. If developed, the wind stations will prevent about $680,977 \mathrm{tCO}_{2}$ per year entering into the local area.

Wind energy potential in Jordan was presented in [9]. About 18,900 GWh per year can be produced by four wind farms. At present, renewable energy produces around $7 \%$ of the total energy of the nation [10]. To fully supply total power demand for the country in 2050, about $40.1 \mathrm{GW}$ of renewable energy needs to be produced, in which wind energy must occupy $4.5 \mathrm{GW}$ to meet the demand, presented by Suhiland Elyasa [11].

Reference [12] studied a $20 \mathrm{MW}$ wind farm in Saudi Arabia. A significant amount of nearly 59.073 GWh was annually produced, accounting for $33.7 \%$ of the plant capacity. Eleven cities in Iran installing wind energy were investigated in [13]. The authors suggested a modified maximum likelihood method for the simulation of energy production of wind farms. A Computational Fluid Dynamics (CFD) model was used to map wind energy potentials for Mauritius island in India [14]. The research carried out the contour maps for wind velocities and electrical power of the Island with a $500 \mathrm{~m}$ resolution. Besides, the reference [15] analyzes the 
consolidation of wind turbines at different wind speeds, tip speed ratio and pitch angle from wind farms at Zafarana and the Gulf of ElZayt. The study [16] investigates the influence of site and size of wind turbines on the economic operation of wind farms. The results show that the economics of wind power plants depend on the site and characteristics of the wind turbines used.

Others have also focused on the impact on the power system stability when a wind farm is installed. To evaluate the impact of wind farms on the power system, there have been many researchers interested in this issue. The reference [17] uses the PSS/E tool to evaluate the voltage stability on substantial wind farms. Similarly, the impacts on Nordic power systems connected with wind power under transient faults was also investigated in [18]. Voltage stability of an integrated offshore station constructed by 72 wind turbines rated to $2 \mathrm{MW}$ each was studied by Vladislav and Hans [19]. The planned wind farms in Penghu Island, Taiwan were studied in transients and system stability, in which tripped-off wind farms from the system had limited impacts on the local power system [20]. Large wind farms influencing power system oscillations were presented by [21]. The research results show that the impact of wind farms on the voltage and frequency of the power systems depend mainly on the type of wind turbines. Therefore, three types of wind power machines are used to study the impact of wind farms on the power systems when increasing wind power capacity into the power system [22]. It is observed from this research that when tripping off a large-capacity wind farm from the power system, the frequency of the power system decreased to $47.6 \%$ and exceeded the threshold of the system stability. Likewise, the reference [23] has proposed a detailed model of wind turbines which is much simpler and more efficient than traditional wind turbines for simulation.

Like other countries, Vietnam is also being investigated for wind energy sources. According to [24], wind energy was developed on a large area of approximately $31,000 \mathrm{~km}^{2}$. Meanwhile Nha-Trang province gets the most land area with averaged wind speed above $10 \mathrm{~m} / \mathrm{s}$ [25], Phu-Quoc Island has wind farms annually producing over $189.63 \mathrm{GWh}$; which was reported by Tran and Chen [26]. Nguyen focuses on the importance of wind power generation and the impacts of $\mathrm{CO}_{2}$ emissions on fuel choices in the coming years [27]. More specifically, Tran presented that a wind farm in Bac-Lieu province rated in $99 \mathrm{MW}$ power capacity could generate 332 GWh and prevent a remarkable amount of 232,470
$\mathrm{tCO}_{2}$ emission annually [28]. Next decades, renewable energy will be a priority in investment to lower $\mathrm{CO}_{2}$ emission into the local environment [29].

However, specific and elaborate impact studies of wind energy generation and operation on power system reliability and stability are still an attractive attention for research. The construction and integration of wind farms into existing power systems are costly and critical investments. It is because wind turbines are big and expensive structures and machines. Therefore, careful consideration and estimation with respect to technical and economic aspects of wind farms need to be taken into account. Otherwise it may lead to a high chance of failed investments. Moreover, the connection of wind power plants into existing power structures has to be examined strictly before actual connections happen to prevent negative effects and even critical breakdown of the entire power systems. To serve as a basis for planning and operating wind power plants according to the plan to come into operation in the near future. This study focuses on solving two main problems: The WasP software is utilized to simulate structures of planned wind farms and gives estimation of annual power generation of planned wind farms built from 3 popular types of wind turbine (1 MW, $2 \mathrm{MW}$ and $3 \mathrm{MW}$ ). Besides, the transient stability analysis such as the disturbances from wind speeds, three-phase bus faults, tripping off wind farms and three-phase line faults are observed by using ETAP software to analyze the impacts of wind farms on the local power system. The study consists of 5 sections: The first section is the introduction followed by the power system description and methodology. Section 3 is the energy yield estimation of each wind farm and $\mathrm{CO}_{2}$ emission analysis. Section 4 is a case study. Last but not least, conclusion and discussion will be presented.

\section{Power System Description and Methodology}

\subsection{Local Power System Description}

Wind farm locations in Southern Vietnam with the highest $500 \mathrm{kV}$ power system are shown in Figure 1. Total rated power of wind power generation is $15,590 \mathrm{MW}$ and total corresponding load demand is 11,100 MW. Underground cables with $11 \mathrm{kV}$ voltage has been installed to connect wind farms to the national power system.

Meteorological and measured wind data in BacLieu and Ca-Mau have been presented in $[24,25$, $28,30]$. The wind data of Soc-Trang and Tra-Vinh 
were simulated by the interpolation tool in WAsP 10. The construction of offshore wind farms is a good condition to get maximum wind flow or speed. The weather condition in the South of Vietnam has remarkable advantages for wind energy generations with a sunny season and a rainy season in a year. Mean annual rainfall is about $164.7 \mathrm{~mm}$. Each year, the relative humidity, average temperature, and atmospheric pressure are about $81.5 \%, 27.6^{\circ} \mathrm{C}$, and $100.9 \mathrm{kPa}$, respectively, which is presented by Joost and Eric [30].

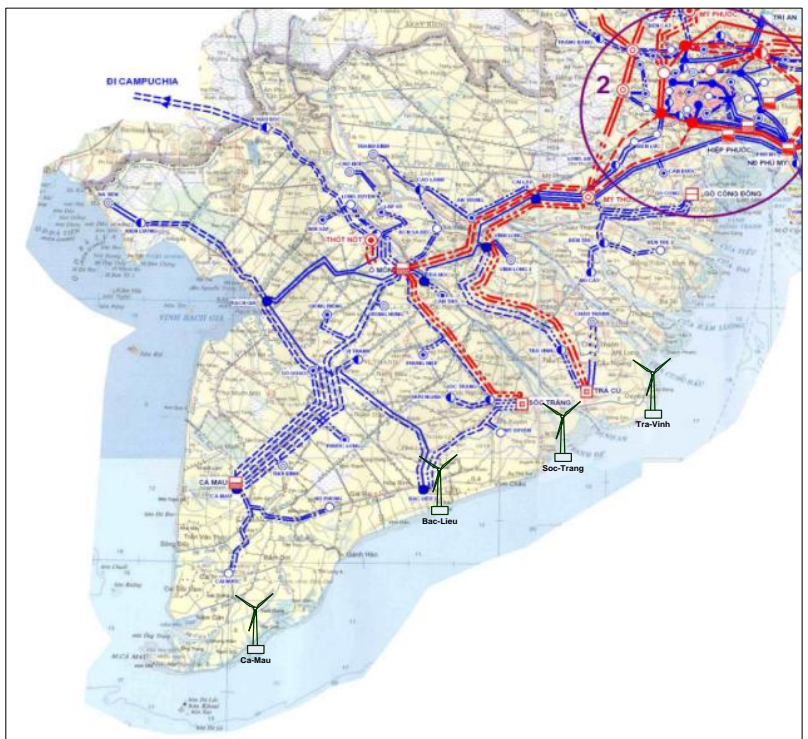

Fig.1: Locations of wind farms on local power system in Southern Vietnam

Due to the advantages from data observations, wind farms are being built in the Southern part of Vietnam. Figure 2 shows the structure of the proposed wind farms.

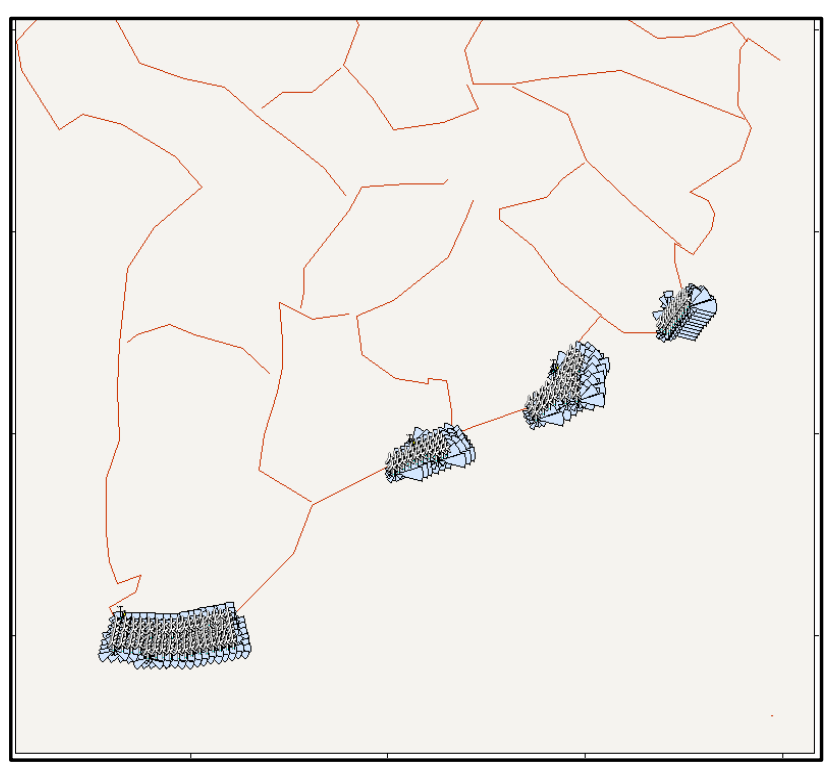

Fig.2: Distributed of wind farms simulated by WasP

\subsection{Methodology}

\subsubsection{Wind farms Energy Production}

The rated capacities produced by planned wind farms every year are estimated by WAsP software. The input is meteorological data in the area where wind farms are planned.

The annual electricity energy production is calculated by the following formula. The detail information is available in [31]:

$$
E=\sum_{x=0}^{25} P_{x} * p(x) * 8760
$$

Where $\mathrm{p}(\mathrm{x})$ is the probability distribution function of annual wind speed $(\mathrm{m} / \mathrm{s})$ and is calculated as:

$$
p(x)=\left(\frac{k}{c}\right) *\left(\frac{x}{c}\right)^{k-1} * e^{-\left(\frac{x^{k}}{c}\right)}
$$

\subsubsection{Transient Stability Analysis}

In this study the ETAP tool was also utilized to simulate the transient stability analysis of the system when planned wind farms are connected to the system. Specifically, the analysis study focuses on the electromagnetic transients of wind farms to the local power system including short circuits at certain buses and short circuits on lines. In addition, it is assumed that a wind disturbance and tripping of the largest wind farm is proposed to obtain the analysis of voltage, frequency and power of the local power system. The analysis is based on the swing and oscillation equations. The detail information is available in [32].

The swing equation is

$$
M \frac{d^{2} \delta}{d t}+D \frac{d \delta}{d t}=P_{m}-P_{e}
$$

And the oscillation equation for the frequency of the system is shown as

$$
f=f_{0}+\frac{f_{0} \Delta P}{2 H \omega_{d} \sqrt{1-\zeta^{2}}} e^{-\zeta \omega_{n} t} \sin \left(\omega_{d} t\right)
$$

\section{Energy yield and $\mathrm{CO}_{2}$ Emission Estimation}

The wind energy production of wind farms is calculated by WAsP 10 program. Figure 3 shows total annual energy generation of each wind farm with 3 types of wind turbine (1 MW, $2 \mathrm{MW}$, and 3 MW). It is noted that the energy production increases as higher rated capacities of wind turbines are installed from $1 \mathrm{MW}$ to $3 \mathrm{MW}$ seen from Figure 3. For example, at the Ca-Mau wind farm, energy 
production of $1 \mathrm{MW}$ and $3 \mathrm{MW}$ wind turbines was 944.28 $\mathrm{GWh}$ and 1,357.77 $\mathrm{GWh}$, respectively. CaMau and Soc-Trang wind farms have higher planned capacity factors (PCF) with $51.7 \%$ and $46.8 \%$, respectively. In addition, the wind farms could produce $2,265.15 \mathrm{GWh}$ annually.

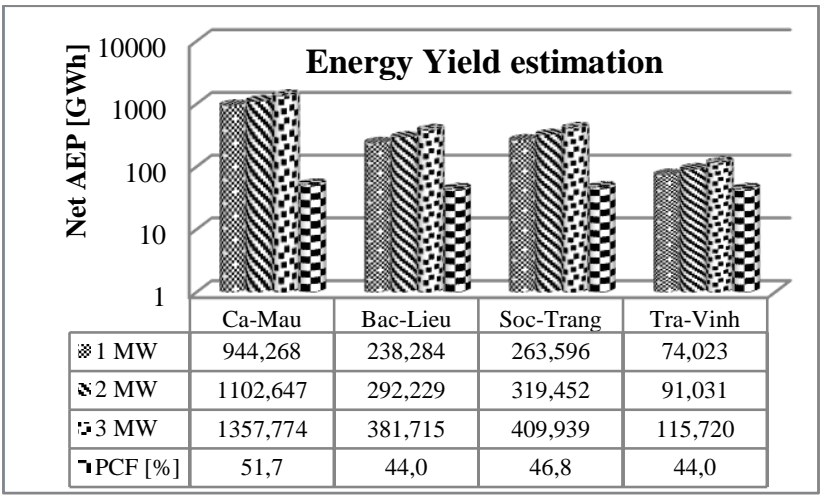

Fig.3: Annual wind energy production of wind farms

Generally, 1 MWh of energy production generates $0.432 \mathrm{tCO}_{2}$ in Vietnam reported by Joost and Eric [30]. If developed, the wind farms could avoid 978,544 $\mathrm{tCO}_{2}$ emitting into the local atmosphere annually. The wind farms, therefore, would contribute to a clean atmosphere in the Southern area of Vietnam.

\section{Impacts of Wind Power Plants on Planned Power System}

\subsection{Disturbances from wind speeds}

Wind speed disturbances are applied for 3 wind farms at Ca-Mau, Bac-Lieu and Tra-Vinh at 3 different times $\left(1^{\text {st }}\right.$ second, $12^{\text {nd }}$ second and $21^{\text {st }}$ second, respectively). The purpose is to observe the effect of each disturbance on the voltages, real power of all wind farms on the local power system. Figure 4 shows effects of the wind speed disturbances at each wind farm with respect to the voltages and real power of the other wind farms on the power system.

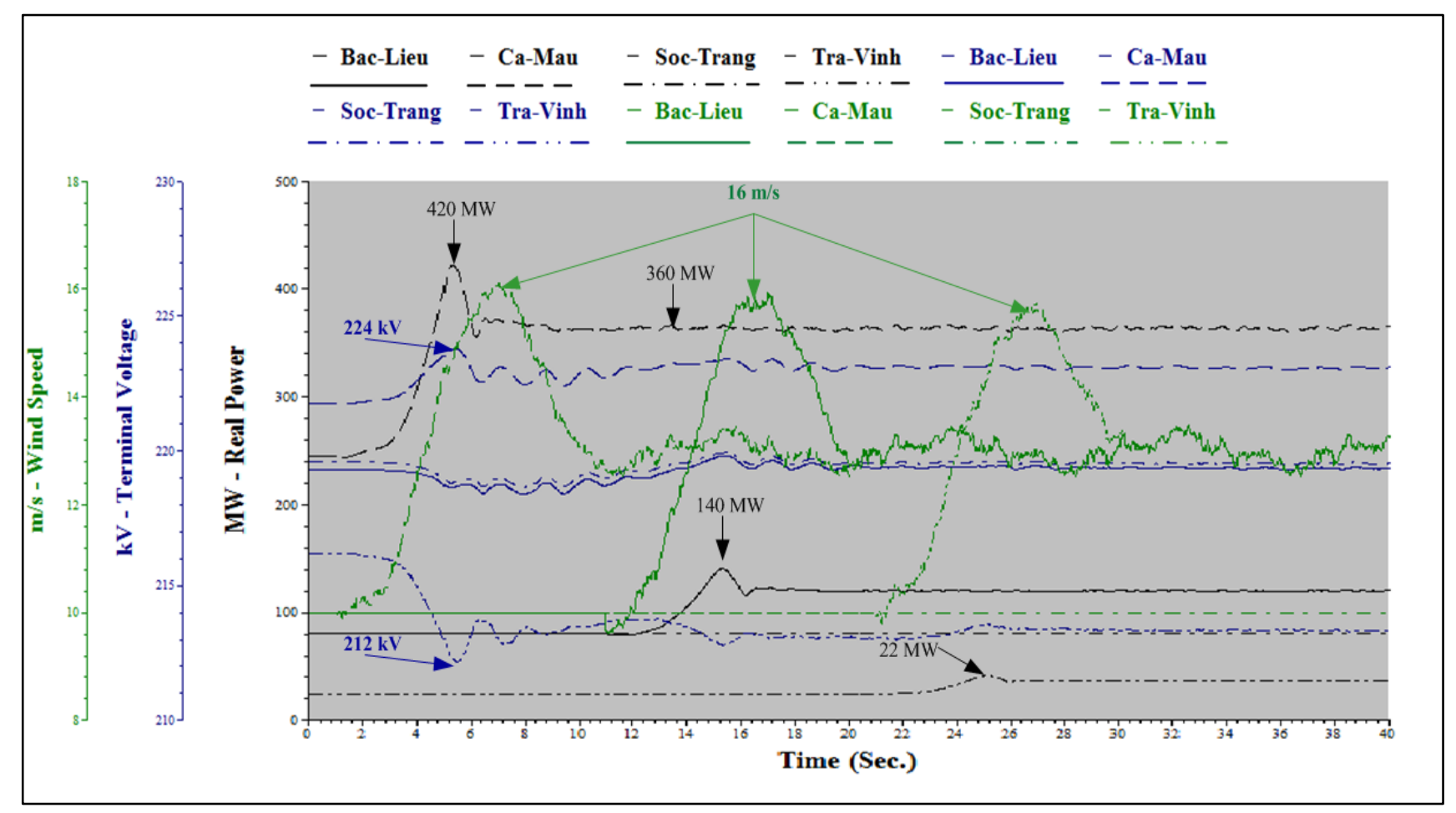

Fig.4: Wind speed disturbances and responses of voltage and power.

Specifically, it is seen that the wind speed suddenly increases from $10 \mathrm{~m} / \mathrm{s}$ to $16 \mathrm{~m} / \mathrm{s}$, then decreases from $16 \mathrm{~m} / \mathrm{s}$ to $13 \mathrm{~m} / \mathrm{s}$, and 4 seconds later becomes steady state at $13 \mathrm{~m} / \mathrm{s}$ with a little noise after the disturbance stopped. Generally, when a wind speed disturbance occurs at a wind farm, only the power at this wind farm is fluctuated, which means the wind speed disturbance at one wind farm does not affect the power of the other wind farms. The wind speed disturbance at the Ca-Mau wind farm has the most effect on its own power compared with at the other wind farms. As demonstrated, the power of the CaMau wind farm increases from $244 \mathrm{MW}$ to $420 \mathrm{MW}$ and drops to $360 \mathrm{MW}$ within 5 seconds. The wind 
speed disturbance at the Ca-Mau wind farm did not impact the power of the other wind farms. However, when the disturbance occurs at the largest wind farm (Ca-Mau), all voltages at the wind farms are fluctuated in which the voltage at Tra-Vinh wind farm was affected most, dropping rapidly from 217

Figure 5 shows the voltage fluctuations, under the wind speed disturbances, at buses where the wind farms are connected on the power system. Under the influence of the disturbance at the $\mathrm{Ca}$ Mau wind farm, the voltage of each bus has slightly varied in the range of $95 \%$ to $105 \%$ while the
$\mathrm{kV}$ to $212 \mathrm{kV}$. The Ca-Mau wind farm voltage increases from $222 \mathrm{kV}$ to $224 \mathrm{kV}$ within $5 \mathrm{~s}$ and maintains at $223 \mathrm{kV}$ before becomes steady state while the voltage of Bac-Lieu and Soc-Trang wind farms oscillates around $220 \mathrm{kV}$ and settles to the steady state rapidly.

disturbances at the other wind farms did not affect the voltages of the buses. Generally, the disturbances from the wind speed do not have significant effects on bus voltages of the power system except for the disturbances at the largest wind farm (Ca-Mau).

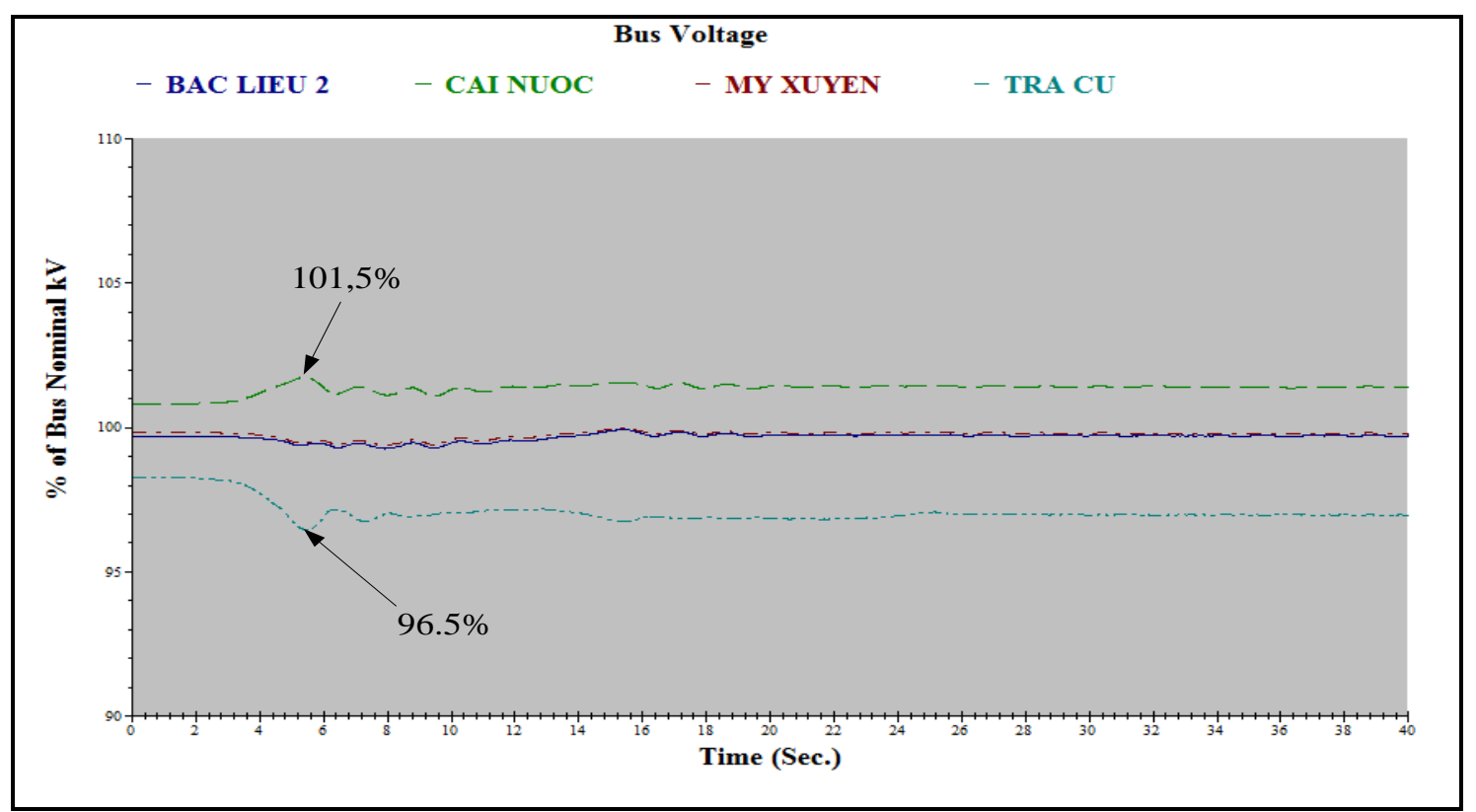

Fig.5: Bus voltages when the wind speed disturbances occur at the wind farms

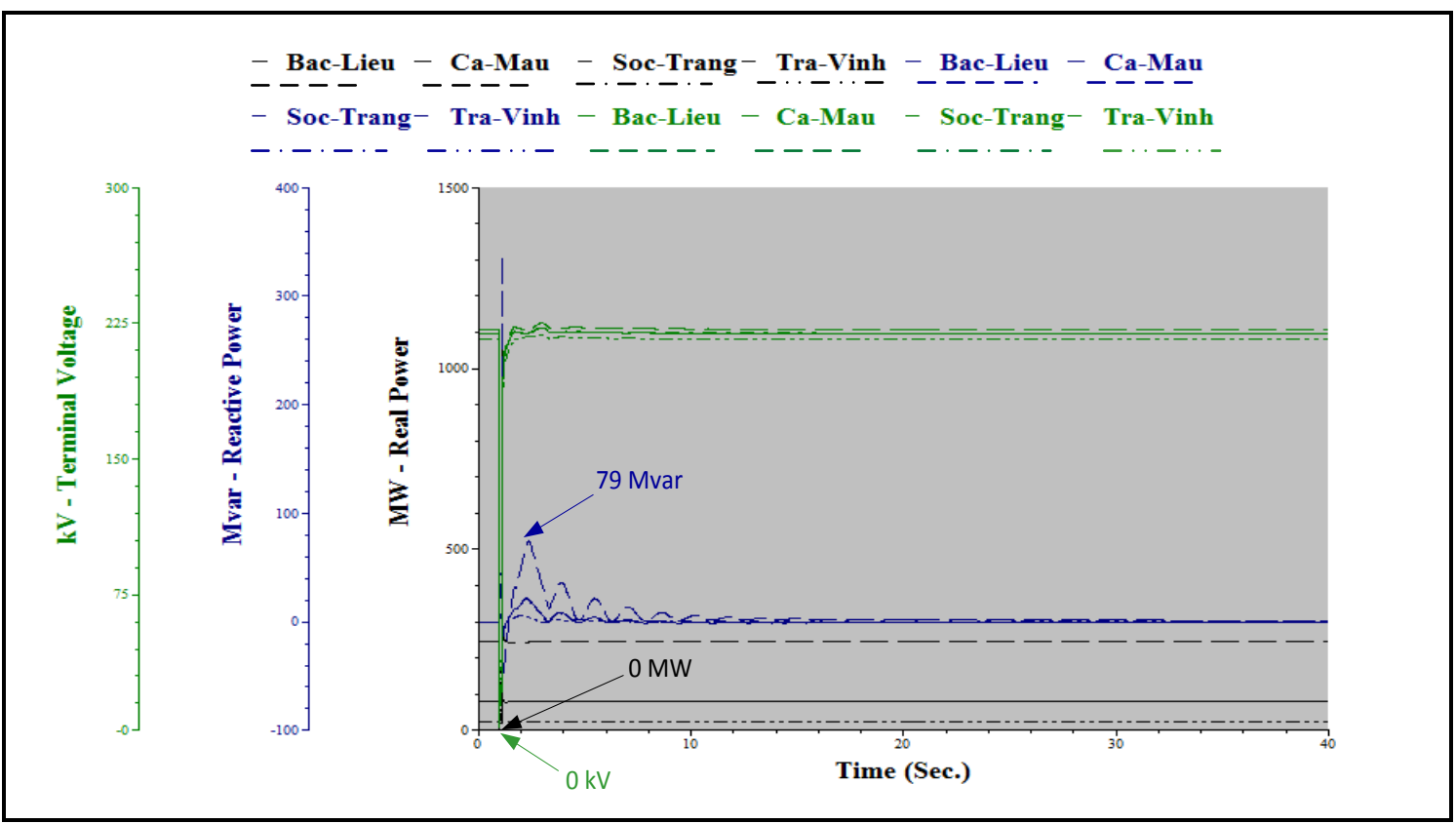

Fig.6: Real powers, reactive powers and terminal voltages of the wind farms when a three-phase fault occurred. 


\subsection{Three-phase Bus Faults}

The dynamic behaviours of wind farms are shown in Figure 6 when the Ca-Mau bus is simulated by a three phase fault. The fault appears at $1^{\text {st }}$ second and disappears after 0.1 second. The wind farms voltages disrupt suddenly to $0,20,25$ and $40 \mathrm{kV}$ at Ca-Mau, Bac-Lieu, Soc-Trang and Tra-Vinh wind farms, respectively. Similarly, all of real and reactive power are also dropped down to zero. After the fault is eliminated at $1.1^{\text {st }}$ second, the voltages and power of all buses are slightly fluctuating before returning to normal conditions. However, there is a remarkable reactive power surge on the $\mathrm{Ca}-\mathrm{Mau}$ wind farm, reaching its highest point at $79 \mathrm{MVar}$. It should be emphasized that when the fault occurs at the Ca-Mau bus, wind farms near the faulted bus are the most significantly affected during the recovery process.

\subsection{Tripping off wind farms}

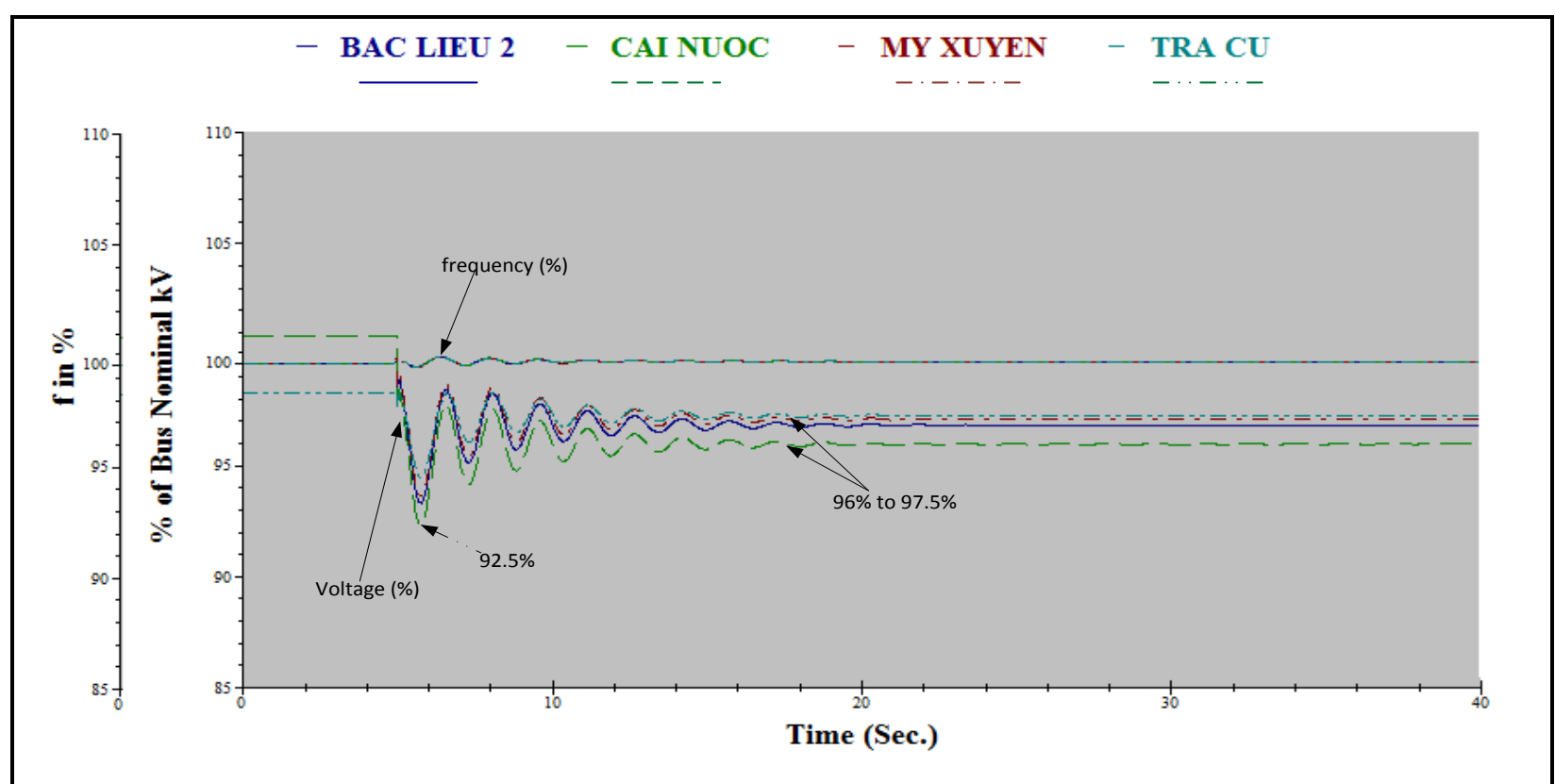

Fig.7: Bus voltages and frequencies was fluctuated when Ca-Mau wind farm was tripping off at $5^{\text {th }}$ second

\subsection{Three-phase Line Fault}

The three-phase fault in the middle of the overhead line connecting between Cai-Nuoc and Ca-Mau buses is shown in Figure 8. It can be assumed that the fault occurs at the $2^{\text {nd }}$ second and clears after 0.1 second. The voltages of wind farms from $210 \mathrm{kV}$ to $230 \mathrm{kV}$ in the normal working condition suddenly drop to $105 \mathrm{kV}, 130 \mathrm{kV}, 132 \mathrm{kV}$ and $135 \mathrm{kV}$ at CaMau, Bac-Lieu, Soc-Trang and Tra-Vinh wind farms, respectively and come back the normal condition in 3 seconds after the fault is clear. It
Figure 7 illustrates voltages and frequencies of buses near wind farms when the Ca-Mau wind farm is tripped off. The frequencies of buses slightly oscillate at $5^{\text {th }}$ second and return to normal condition after 10 seconds. The voltage of the Cai-Nuoc bus is the most affected. It drops to $92.5 \%$ and is unsteady during the next 10 seconds before returning to steady state. Additionally after the $20^{\text {th }}$ second, all bus voltages return to normal condition which is in the range of $96 \%$ to $97.5 \%$ of the normal voltages.

The simulation results are explained by the equations (3) and (4). The system suddenly loses an amount of power $\Delta \mathrm{P}$, so the frequency and voltage drop instantaneously, then recovers to a new steady state due to the system's inertia (D). Here, the voltages and frequencies of the system at the buses are fluctuated and settled to a new value after the system has lost $300 \mathrm{MW}$ due to the Ca-Mau wind farm being tripped off from the power system. The simulation results are consistent with the studies $[20,22]$ when a wind farm is suddenly tripped off of the power system. 
the fault on the transmission line does not cause tripped off any wind farms as well as affect the

operating condition of the power system.

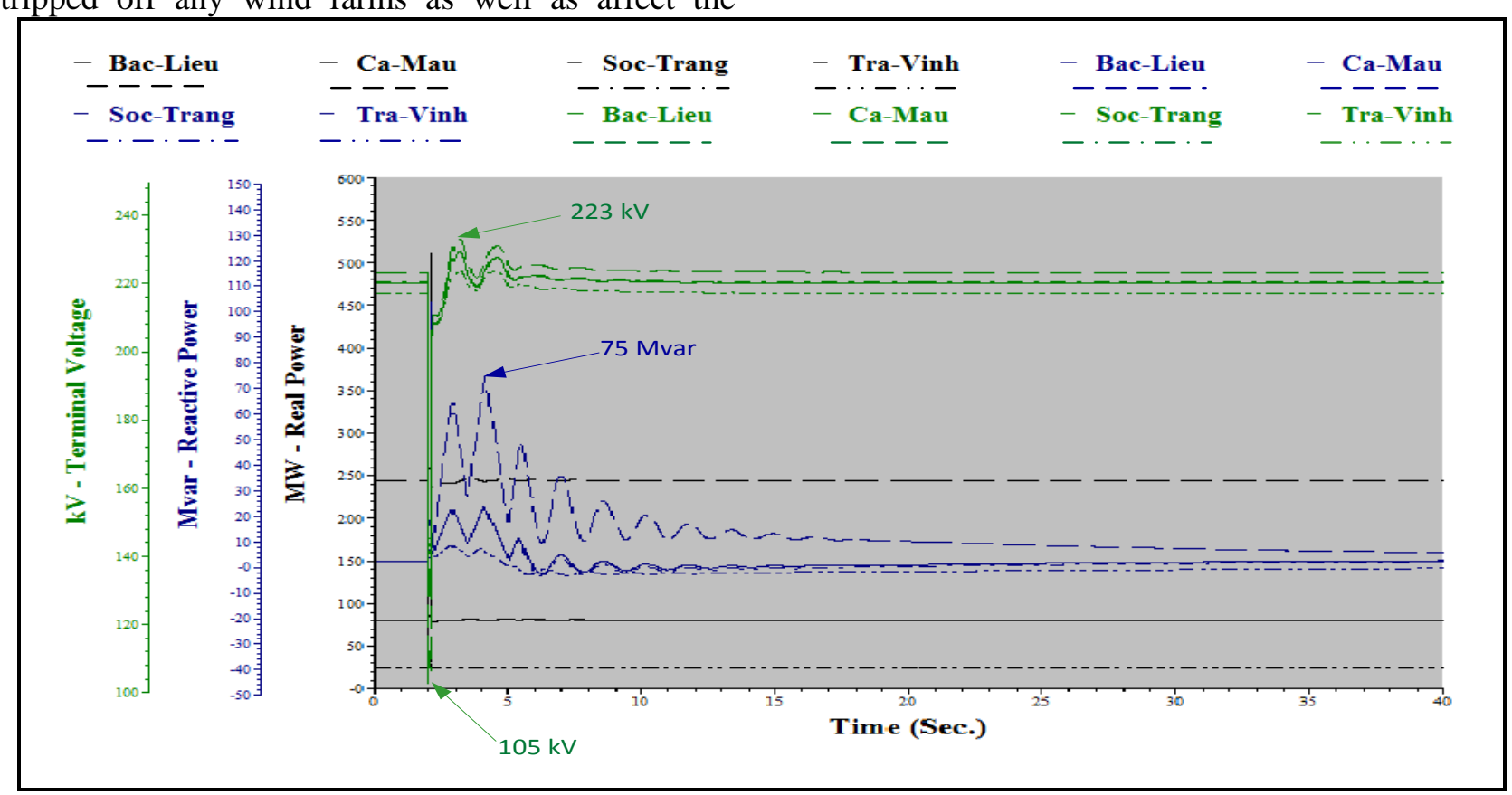

Fig.8: Wind farms' transient status when a simulation of three-phase fault is on line.

\section{Discussion and Conclusions}

This study simulated the impacts of four planned wind farms on the local power system in the Southern region of Vietnam. The electrical energy generated annually for each wind farm is estimated using the WAsP 10 software. In addition, the impacts of wind farms on the power system are analyzed through four transient cases including the wind disturbances, the bus fault, the tripping off wind farm and the fault in the middle of the transmission line. The results show that the case of fault in the transmission line has the worst impact on the power system compared to other cases; However, after eliminating the fault, the power system stays stable at the new condition. Therefore, we should consider strictly the fault protection system on transmission lines before a wind farm is connected. In addition, connecting the wind farms leads to the remarkable advantages for the economy and environment. The results indicate that the large energy production of 5,265.15 GWh per year generated from wind farms contributes to cut off the fossil fuel sources in electrical generation. Besides, avoiding 978,54 $\mathrm{tCO}_{2}$ emitting into the environment from wind farms is very wonderful and deserves to be invested.

In general, the study simulated and evaluated the four wind farms with a variety of specific transient cases. The outcomes indicate that wind farms only slightly impact the power system operation when any faults occur. Wind is a great renewable energy in terms of replacing fossil fuel sources and being friendly environment. The study findings should contribute to the exploitation and operation of the enormous potential of wind energy in the Southern power system of Vietnam.

The details of simulation on four practical wind power plants situated in Southern Vietnam evaluate the energy generation, $\mathrm{CO}_{2}$ emission limits, and the effects of wind farms on the national power system. Some observations can be derived as follows:

- Wind turbines rated in $3 \mathrm{MW}$ for all wind farms will generate the most energy in the same rate capacity of wind farms. Total substantial amount of energy capacity of 2,265.15 GWh annually will be generated if they are well investigated for four wind farms.

- The capacity factor will occupy $46.8 \%$ and $51.7 \%$ in Soc-Trang and Ca-Mau wind farms, respectively.

- The four wind farms could avoid 978,54 $\mathrm{tCO}_{2}$ emitting into the environment.

- The wind speed disturbances at any wind farm will not significantly influence the real power, the voltages at the other wind farms, and the system buses. Only the largest wind farm , CaMau, has little effect on the power system. And if there is any three-phase fault at buses near wind farms, wind farms still maintain the normal operating condition.

- When the biggest wind farm, the wind farm at $\mathrm{Ca}-\mathrm{Mau}$, is assumed to be tripped off from the 
power system at $5^{\text {th }}$ second, the voltages of the neighbouring buses of the faulted wind farm fluctuated in the next 13 second before recovering to the normal state at the $20^{\text {th }}$ second. In addition, the frequency is slightly affected in this case.

- A three-phase fault in the middle (50\%) of the line connecting Cai-Nuoc and Ca-Mau does not cause tripping off any wind farms.

The limitation is that this study has not assessed the impact of diverse renewable energy sources on the power system at the same time. For example the solar energy source has been growing a very significant installed capacity on the power system in recent years. In addition, the study has not analysed the maximum power capacity of renewable energy sources, especially the wind power that can be connected to the power system of the Mekong Delta to ensure the stable operating system.

The above limitations can be further investigated to comprehensively assess the impact of all renewable energies on the regional power system at the same time as well as identify the maximum amount of capacity of renewable energy sources that can be connected to the regional power system in the future.

\section{Acknowledgments:}

This research is fully funded by Tra Vinh University, Vietnam under the contract No. 212/HĐ.HĐKH-ĐHTV dated on September 16, 2019.

\section{References:}

[1] Renewables, R., Renewables Global Status Report 2019 REN21, 2019.

[2] Himri, Y., S. Himri, and A.B. Stambouli, Wind power resource in the south-western region of Algeria. Renewable and Sustainable Energy Reviews, 2010. 14(1): p. 554-556.

[3] Himri, Y., et al., Wind energy for rural areas of Algeria. Renewable and Sustainable Energy Reviews, 2012. 16(5): p. 2381-2385.

[4] Himri, Y., et al., Wind power potential assessment for three locations in Algeria. Renewable and Sustainable Energy Reviews, 2008. 12(9): p. 2495-2504.

[5] Himri, Y., A. Boudghene Stambouli, and B. Draoui, Prospects of wind farm development in Algeria. Desalination, 2009. 239(1): p. 130138.

[6] Rahmani, K., et al., Wind Power Assessment and Site Matching of Wind Turbines in Lootak of Zabol. INTERNATIONAL JOURNAL of RENEWABLE ENERGY RESEARCH, 2014.
Vol.4: p. 965-976.

[7] Chen, T.H., Van Tan Tran, Nien Che Yang, and Ting Yen Hsieh, Wind Energy Potential in Taiwan. Applied Mechanics and Materials January 2013. 284-287

[8] Chen, T.-H. and V.-T. Tran, Prospects of wind energy on Penghu Island, Taiwan. Wind and Structures, 2015. 20: p. 1-13.

[9] Alsaad, M.A., Wind energy potential in selected areas in Jordan. Energy Conversion and Management, 2013. 65: p. 704-708.

[10] Abu-Rumman, G., A.I. Khdair, and S.I. Khdair, Current status and future investment potential in renewable energy in Jordan: An overview. Heliyon, 2020. 6(2): p. e03346.

[11] Kiwan, S. and E. Al-Gharibeh, Jordan toward a $100 \%$ renewable electricity system. Renewable Energy, 2020. 147: p. 423-436.

[12] Rehman, S., A. Ahmad, and L.M. Al-Hadhrami, Development and economic assessment of a grid connected 20MW installed capacity wind farm. Renewable and Sustainable Energy Reviews, 2011. 15(1): p. 833-838.

[13] Sedghi, M., S.K. Hannani, and M. Boroushaki, Estimation of weibull parameters for wind energy application in Iran's cities. Wind and Structures, 2015. 21(2): p. 203-221.

[14] Dhunny, A.Z., M. Lollchund, and S. Rughooputh, A high-resolution mapping of wind energy potentials for Mauritius using Computational Fluid Dynamics (CFD). Wind and Structures An International Journal, 2015. 20: p. 565-578.

[15] Ibrahim R Mohammed, A.A.S., Ahmad M. Saleh, Consolidity analysis of wind turbines in wind farms. International Journal of Renewable Energy Research, 2020. Vol. 10(No. 1).

[16] S. Bajaj, K.S.S., Effect of site and size of wind turbine on its economic operation. International Journal of Circuits, Systems and Signal Processing, 2019. 13(1998-4464).

[17] Akhmatov, V., et al., Modeling and transient stability of large wind farms. International Journal of Electrical Power \& Energy Systems, 2003. 25: p. 123-144.

[18] Jauch, C., et al., Simulation of the impact of wind power on the transient fault behavior of the Nordic power system. Electric Power Systems Research, 2007. 77(2): p. 135-144.

[19] Akhmatov, V. and H. Knudsen, An aggregate model of a grid-connected, large-scale, offshore wind farm for power stability investigations-importance of windmill mechanical system. International Journal of Electrical Power \& Energy Systems, 2002. 
24(9): p. 709-717.

[20] Wu, Y.-K., G.-Y. Han, and C.-Y. Lee, Planning 10 onshore wind farms with corresponding interconnection network and power system analysis for low-carbon-island development on Penghu Island, Taiwan. Renewable and Sustainable Energy Reviews, 2013. 19: p. 531540.

[21] Slootweg, J.G. and W.L. Kling, The impact of large scale wind power generation on power system oscillations. Electric Power Systems Research, 2003. 67(1): p. 9-20.

[22] Margaris, I., et al., Dynamic security issues of autonomous power systems with increasing wind power penetration. Vol. 6. 2010.

[23] Lafont, F., et al., First Steps Toward a Simple but Efficient Model-free Control Synthesis for Variable-speed Wind Turbines. International Journal of Circuits, Systems and Signal Processing, 2021. 14: p. 1181-1191.

[24] Nguyen, K.Q., Wind energy in Vietnam: Resource assessment, development status and future implications. Energy Policy, 2007. 35(2): p. 1405-1413.

[25] Tran, V.T., Chen, T.H. and Hsiehd, T.Y. , Wind Energy Potential in Vietnam, in Proceedings of the IASTED Asian Conference Power and Energy Systems. 2012.

[26] Tran, V.-T. and T.-H. Chen, Wind energy resources on Phuquoc Island, Vietnam. Energy Sources, Part A: Recovery, Utilization, and Environmental Effects. 38(2016): p. 16121619.

[27] Nguyen, K.Q., Impacts of wind power generation and $\mathrm{CO} 2$ emission constraints on the future choice of fuels and technologies in the power sector of Vietnam. Energy Policy, 2007. 35(4): p. 2305-2312.

[28] Tran, V.-T. and T.-H. Chen, Assessing the wind energy for rural areas of vietnam. International Journal of Renewable Energy Research, 2013. 3: p. 523-528.

[29] Do, T.H. and H. Clemens, A power development planning for Vietnam under the CO2 emission reduction targets. Energy
Reports, 2020. 6: p. 19-24.

[30] Joost, S.a.E., A. , Wind energy potential in Vietnam. 2018.

[31] Pan, Y., et al., Feasibility analysis on distributed energy system of Chongming County based on RETScreen software. Energy, 2017. 130: p. 298-306.

[32] Saadat, H., Power system analysis. 2004, PSA Publishing.

\section{Contribution of Individual Authors to the Creation of a Scientific Article (Ghostwriting Policy)}

Minh-Hoa Nguyen carried out the conceptualization, formal analysis, investigation, methodology, supervision, validation, review and editing.

Van-Tan Tran has done the formal analysis, investigation, software, supervision, and original draft.

Tan-Hung Pham did the data collection, investigation, and visualization.

Thanh-Luu Cao was responsible for the investigation, resources, project administration, and writing.

\section{Sources of Funding for Research Presented in a Scientific Article or Scientific Article Itself}

This study was fully funded by the research foundation of Tra Vinh University under the contract No. 212/HĐ.HĐKH-ĐHTV dated on September 16, 2019.

\section{Creative Commons Attribution License 4.0 (Attribution 4.0 International, CC BY 4.0)}

This article is published under the terms of the Creative Commons Attribution License 4.0 https://creativecommons.org/licenses/by/4.0/deed.en _US 